\title{
O ANTI-PSIQUÊ: REFLEXÕES SOBRE CORPOS E SEUS DUPLOS NA AMAZÔNIA
}

LEIF GRÜNEWALD ${ }^{1}$

$U F F$

RESUMO: Este ensaio parte de uma interrogação sobre como pensar uma noção de alma que não fosse redutivel ao dualismo 'corpo-substância' e, logo, a uma imagem que é a simples figuração e a mera representação de um corpo humano. Para tanto, este ensaio revisita as etnografias araweté e yanomami e cruza seus dados com as discussões promovidas por Gilles Deleuze a respeito de outro tipo particular de imagem, a imagem cinematográfica; e por Tânia Stolze Lima sobre a noção de ponto de vista. Ao fazê-lo, este artigo finda por refletir sobre várias maneiras de conceber a ideia de alma, tendo em vista as maneiras e mecanismos que compõem e coordenam essa ideia, impedindo que ela congele enquanto uma representação de um corpo humano.

PALAVRAS-CHAVE: corpo; alma; Amazônia; representação; ponto de vista.

ABSTRACT: This article focus on the question about how to talk about a soul without reducing it to a mere image that represents the human body. In order to do so, this thesis returns the ethnographic data on the Arawete and Yanomami peoples, to the cinema studies made by Gilles Deleuze and to the classic discussions that play an important role in current Amerindian Ethnology studies, through the texts of Tânia Stolze Lima. In doing so, this thesis proposes a reflection on different ways of thinking the notion of 'soul', stressing the ways it offers resistance to the stabilization, representation and condensation into a single image that stands for a body.

KEYWORDS: body; soul; Amazonia; representation; point of view.

\footnotetext{
${ }^{1}$ Possui graduação em Ciências Sociais pela Universidade Federal do Espírito Santo, mestrado em Antropologia Social pela Universidade Federal Fluminense e é doutorando em Antropologia Social pela mesma instituição. Tem interesse na área de Etnologia Indígena, em particular nos sistemas sociocosmológicos ameríndios e suas transformações na Amazônia e no Chaco Paraguaio. E-mail: leif_grunewald@yahoo.co.uk .
}

Espaço Ameríndio, Porto Alegre, v. 6, n. 2, p. 249-268, jul./dez. 2012. 


\section{Introdução}

Eis no que consiste o ensaio abaixo: um pequeno apanhado de dados e uma reunião de ideias extraídas das etnografias de outros etnólogos de forma a realçar algumas relações pouco exploradas, sem esgotá-las. Como um todo, se poderia dizer que ele trata da relação entre corpo e alma em dois povos amazônicos e, especificamente, ele se atém a questão de como (re)pensar uma ideia de alma que parece escapulir constantemente da maneira tradicional como o tema é tratado em um pequeno conjunto de etnografias sobre povos sul-ameríndios: como uma imagem simétrica ao corpo de uma pessoa, sua pura representação. Meu método aqui consiste, portanto, em fundir os estudos sobre a noção de pessoa em algumas sociocosmologias com a argumentação de Lima (1996) sobre a noção de ponto de vista e com aquele realizado por Gilles Deleuze (1990) sobre outros tipos peculiares de imagem (nomeadas ali de 'imagem-tempo' e de 'imagemmovimento'), usando como gancho o fio da imagem não representacional, para tratar então a alma como uma imagem irredutível à pura representação do corpo de uma pessoa humana. O que relacionaria então as imagens cinematográfica e a anímica é o fato de que ambas não são imagens que representam ou recompõem um movimento externo. Ao contrário, ambas já são, por si só (e antecipadamente), movimento.

Mas isso não é tudo. Essa reunião de ideias extraídas das etnografias de outros etnólogos é também uma tentativa de complementar ideias que restaram pouco desenvolvidas ou malexploradas em minha dissertação de mestrado (GRÜNEWALD, 2011) sobre as ideias de corpo e de alma entre os Araweté, os Bororo e os Yanomami, na qual busquei desenvolver um modelo para a ideia de alma que articulasse as noções de imagem e de representação de forma a não reduzir a imagem corporal nomeada de alma à pura repetição das ações realizadas por uma pessoa. Pois bem. Se esse modelo focalizava a ideia de alma e sua relação com a noção de imagem, deixando em segundo plano a representação, ele também se detinha sobre a possibilidade de organizar essas ideias em torno de um eixo de 
transformações, para o qual as ideias de corpo e de alma tal como mobilizadas por esses povos se definiam como atualizações de uma mesma estrutura que nomeei ali de Anti-Psiquê ${ }^{2}$. Não articulei, entretanto, a tal estrutura Anti-Psiquê às suas atualizações nas sociocosmologias de diferentes povos ameríndios. Em particular, não enfrentei a questão de se essas atualizações seriam, para utilizar o vocabulário estruturalista, de 'forma' ou realmente de 'estrutura'. Na dissertação, restringi-me a apresentar o material etnográfico desses povos indígenas e distingui-los entre si, procurando determinar os pontos de aproximação e de afastamento entre eles, identificando, a partir do cotejo desse material, a existência de uma mesma condição virtual - atualizável de maneiras distintas pelos ameríndios - que faz da alma (enquanto imagem do corpo de uma pessoa) a materialização de uma singularidade individual irredutível à pura repetição dos movimentos do corpo ao qual se encontra atrelada.

Relendo agora essa formulação a respeito do Anti-Psiquê, reconheço nela um conjunto de insuficiências (ou mesmo de derrapagens analíticas que só pude perceber depois de realizá-la): em primeiro lugar, ela parece obliterar os processos de como uma 'almacorpo-imagem' (i.e., uma alma que é corpo e que é imagem deste) se reflete no corpo de uma pessoa humana (sua imagem 'atual'), que, por seu lado, é envolvida e reflete o cosmos ameríndio. Nesse mesmo movimento, ela também parece pressupor uma espécie de 'natureza' para o movimento (e seu risco) de como a alma-corpo-imagem ganha independência e se atualiza em outros circuitos que não só o dos humanos. Em segundo lugar, essa mesma formulação inicial a respeito do Anti-Psiquê não explica satisfatoriamente a relação de mutualidade entre um corpo e uma alma, isto é, como um corpo e sua alma-corpoimagem relacionam-se entre si, compondo uma espécie de corpo bifacial (uma delas 'atual', isto é, o próprio corpo físico de uma pessoa; e a outra 'virtual', a alma-corpo-imagem que está atrelada a ele) em torno de uma 'região de indiscernibilidade'3 (para me expressar como

\footnotetext{
${ }^{2}$ Psiquê era reputada ser, pelos gregos, a personificação da alma na Terra, e também, aos meus olhos, a protagonista de uma relação obcecada entre imagem/alma e a simples representação de um corpo.

${ }^{3} \mathrm{O}$ leitor ou a leitora deve ser alertado(a) para o seguinte: a minha hipótese sobre a existência de uma região de indiscernibilidade entre um corpo e sua alma-corpo-imagem se poderia formular assim: tal é a
}

Espaço Ameríndio, Porto Alegre, v. 6, n. 2, p. 249-268, jul./dez. 2012. 
DELEUZE, 1990) entre o corpo de uma pessoa e sua alma-corpoimagem; ou como o corpo e a alma-corpo-imagem inscrevem-se em circuitos de amplitude variável com outros seres que povoam o cosmos ameríndio: os espíritos, os duplos de animais, entre outros.

Foram esses passos que me escaparam na elaboração do último capítulo da dissertação, talvez por só ter reconhecido a importância de ideias como as de circuito, mutualidade, bifacialidade, e indiscernibilidade (expressas na filosofia de Gilles Deleuze) depois de tê-lo finalizado. Assim sendo, o objetivo desse texto é, claro, superar essas insuficiências. Para tanto, vou tomar a ideia de 'imagem-cristal' (DELEUZE, 1990) - caracterizada por esse autor como aquela dotada de duas faces (uma atual e outra virtual) inconfundíveis entre si e arranjadas em torno de uma 'região de indiscernibilidade' - como análoga à relação entre o corpo de uma pessoa humana e sua almacorpo-imagem, na qual cada um deles tomaria, a exemplo da 'imagemcristal', o papel do outro numa relação de pressuposição recíproca, ou de reversibilidade.

A fim de basear minha análise e reexaminar os problemas que apenas mencionei acima, vou começar por uma exposição geral e pela comparação das ideias de corpo e de alma tal como mobilizadas por dois grupos ameríndios situados no Brasil e/ou nas porções da Amazônia Venezuelana: os Araweté, um povo falante de uma língua tupi-guarani, habitante de uma única aldeia no curso do médio Ipixuna, um tributário da margem direita do rio Xingu, no sudeste do estado brasileiro do Pará; e os Yanomami, um povo caçador-agricultor que habita as terras de uma seção ocidental da fronteira entre o Brasil e a Venezuela na região do interflúvio Orinoco-Amazonas - formada pelos afluentes da margem direita do rio Branco e da margem esquerda do rio Negro.

O fio utilizado para ligar esses grupos são os temas da morte e das situações em que o corpo físico de uma pessoa humana se encontra em estados de inconsciência (seja este dado nos períodos de sono ou nos casos de doença). Para realizar este exercício, examinarei primeiramente esses dois exemplos ameríndios descrevendo os adormecido, doente, etc.) a vê tal qual o corpo físico daquele que se encontra inconsciente.

Espaço Ameríndio, Porto Alegre, v. 6, n. 2, p. 249-268, jul./dez. 2012. 
movimentos das almas, as modificações que ela pode provocar no corpo de uma pessoa humana e as relações que pode se entreter com formas não humanas de alteridade enquanto três passos de um processo de 'atualização' da alma (tida como condição virtual devido a sua característica de ser amplamente generalizada, como sugeriu Viveiros de Castro (1996), entre os centros de agência capazes de ocupar um ponto de vista) e de autonomização perante o corpo físico de uma pessoa - as duas partes do processo que aos meus olhos caracterizaria o funcionamento do Anti-Psiquê.

Ainda que a escolha por um percurso como este e o desenvolvimento que darei aos temas importados da etnografia amazônica possam parecer razoavelmente desajeitados ao longo das próximas páginas, foi esta a maneira que encontrei para conciliar a etnografia de povos das terras baixas da América do Sul com a filosofia de Gilles Deleuze, a fim de conceber a noção de Anti-Psiquê como heurística. Mas isso, claro, de um lado. De outro, a rumada por esta direção remete também à própria ordem em que estas questões saltaram diante de meus olhos. Nesse sentido, o tempo e o movimento da análise que pretendo empreender aqui já são, de certa forma, uma espécie de reconstituição sui generis do próprio amadurecimento da ideia sobre o Anti-Psiquê.

\section{Alguma alma}

É então da ideia de alma tal como mobilizada pelos Yanomami que partirei, apostando que ela fará evidente os movimentos, as relações e as qualidades que apenas mencionei acima.

Dizem os Yanomami que seu bei ōshi, sua "interioridade metafísica"4 (para dizer como Albert (1985, p. 140)) - uma junção entre 'imagem' e 'energia corporal individual', como se esta fosse uma espécie de 'conjunto' de elementos espirituais que quando integrados constituem a pessoa humana -, tem um papel importante na nosologia

\footnotetext{
${ }^{4}$ Para os Yanomami, a oposição entre bei ōshi e a pele de uma pessoa, bei sïke, não é redutível a uma oposição tal qual a existente entre interior e exterior. Se bei sïke designa a pele de uma pessoa, ele também designa seu conjunto anatômico de órgãos internos.
}

Espaço Ameríndio, Porto Alegre, v. 6, n. 2, p. 249-268, jul./dez. 2012. 
de suas doenças: seres (sobre)naturais poderão se apoderar dele, fazendo, assim, as pessoas doentes. Isso é, logicamente, apenas uma possibilidade. Mas há ainda algo mais grave a que estão sujeitos os Yanomami: se esses seres conseguirem devorar o beioshi de uma pessoa antes que um xamã tenha conseguido recuperá-lo, eis que ocorre então a morte de uma pessoa humana.

Da primeira subcategoria que comporia esta interioridade metafísica beioshi concebida tal como um sistema discreto e descontínuo composto por quatro subcategorias distintas, bei bihi, se poderia dizer inicialmente o seguinte: na boca dos Yanomami este termo designa, literalmente, um rosto e suas expressões, mas para o caso que realmente nos interessa aqui, ele é a metáfora utilizada pelas pessoas desse povo para se referirem aos estados de consciência e à subjetividade de uma pessoa humana. Mas isso não é tudo, pois, na glosa yanomami, esse mesmo termo designa o princípio de todas as emoções às quais uma pessoa humana é sensível. Assim, quem diz bei bihi diz sobre o próprio pensamento, bihi kuu ('pensar-falar'), diz também sobre perda de consciência, bihi mahuru, ou sobre um estado de angústia e hesitação, bihi hetemu ('pensamento-buscar-agir-como'), sobre um estado de cólera e enfurecimento, bihi wayu (pensamentoperigoso) ou mesmo sobre um par que é absolutamente temido pelos Yanomami: a saudade e a ansiedade, bihi wani e bihi biyëkëo, respectivamente.

Se o bei bihi faz referência às emoções e aos estados de consciência, também há, entre os Yanomami, uma segunda subcategoria associada à origem do pensamento inconsciente: bei a në boreb $^{5}$. Como interveio Albert (1985, p. 142), deve-se notar que os Yanomami fazem uso dessa noção para designar o duplo interior que é considerado como a origem de todas as manifestações de pensamento/comportamento que se revelam aos olhos de outrem na forma de movimentos e expressões involuntários ocorridos nos episódios oníricos, nas alterações momentâneas de consciência provocadas pela dor aguda ou pela doença (física/mental) grave e nos

\footnotetext{
${ }^{5}$ Bei a në borebł em sua forma bore-a é utilizado pelos Yanomami para designar o espectro de uma pessoa recém-falecida ou aquele liberado momentaneamente do corpo de um humano adormecido, oposto a uma pessoa viva, temirime thë. Ver Albert (1985).
}

Espaço Ameríndio, Porto Alegre, v. 6, n. 2, p. 249-268, jul./dez. 2012. 
transes (xamânicos ou não) que acontecem sob o efeito de alucinógenos. Conta-se entre os Yanomami que, por razão da morte ou dos períodos em que passa adormecida, a forma espectral que existe no interior do envelope corpóreo de uma pessoa é capaz de se desvencilhar e rumar para longe do corpo 'falecido' (seja ele 'parcialmente' falecido ou o corpo realmente falecido). Se há a morte de facto, então a forma espectral rumará para o hetu mis aguardam ansiosamente, como se estivessem esperando alguém que estava já há muito tempo ausente.

Mas quando o caso é outro e a 'morte' é simplesmente de jure (os períodos que o corpo está adormecido, por exemplo), as formas espectrais lançam-se pela floresta em busca de frutas para saciar sua enorme fome, ou simplesmente atacam as roças de outrem, devorando todas as bananas-da-terra que encontrarem em seu caminho. Assim sendo, se poderia apontar que os acontecimentos ocorridos com o bei a në borebł de uma pessoa humana durante o 'intervalo' que se instala entre a forma espectral (capaz de passear e adentrar fundo as florestas/roças em busca de comida) e o envelope corporal que repousa 'morto' (seja de facto ou apenas de jure) também figuram nas narrativas yanomami como causas para o sofrimento e as patologias que por ventura venham a acometer os humanos vivos.

Acresce-se ao bei a në borebł e ao bei bihi o bei a në ütübi, que designa, lato sensu, todas as formas de reprodução: a sombra de um corpo; os seus reflexos; os modelos reduzidos de um objeto, wāha $\bar{u} t u \bar{b} \bar{r}$; as fotografias; os desenhos; os brinquedos; as vozes registradas em gravações, etc.; e está localizado, a rigor, no seio da forma espectral bei a në borebł. O que é, no entanto, interessante é que a noção de bei a në ütübi também é, como destacaram Albert (1985, p. 147) e Lizot (2007, p. 292), concebida como uma forma absolutamente agressiva e

\footnotetext{
${ }^{6}$ Segundo os Yanomami, este é um domínio de abundância, onde há fartura de mel, frutos silvestres e pecaris e onde se reúnem as almas dos mortos em uma grande casa coletiva por ocasião do falecimento de uma pessoa humana. Dada a morte, as almas aguardam a chegada da alma do recém-falecido ao hetu misi como se estivessem aguardando um saudoso parente que estava ausente há muito tempo, e lá uma nova rede de algodão branco já o espera, na qual o novo residente do hetu misi se instala com toda naturalidade. Mas que frise-se que nem todas as almas estão aptas a rumarem para esta morada celeste. Àqueles mortos por flechas resta contentar-se com a morada junto com os shirãkõri, que vivem nas regiões pedregosas da Terra Yanomami. Àqueles que foram mesquinhos durante a vida resta, por outro lado, queimar em uma fogueira, shopari wakë, onde estas almas serão definitivamente eliminadas da existência. Para uma interpretação adicional, ver Lizot (2007).
}

Espaço Ameríndio, Porto Alegre, v. 6, n. 2, p. 249-268, jul./dez. 2012. 
dotada do poder de causar enfermidades nos humanos vivos. Postula-se entre os Yanomami que, diferentemente do bei a në borebł (que, como se sabe, está sempre sujeito à agressão de outrem quando 'descolado' do corpo físico), o bei a në ütūbì é algo como um espectro no qual a pessoa se transformará por ocasião de seu falecimento, extremamente perigoso e patogênico quando deslocado do interior do bei a në borebí: sob a forma de espectro, o bei a në ütübi pode causar enfermidades às outras pessoas humanas devido a sua agressividade desmedida, que o impulsiona a roubar o princípio vital dos humanos.

Detalhe ainda mais interessante é que, durante as expedições de guerra, os xamãs podem golpear o bei a në ütübï de seus inimigos na noite que antecede $o$ ataque com força suficiente para fazer com que os inimigos fujam inconscientes de suas casas. Ora, mas se o ataque xamânico sobre o bei a në ütübi de outrem é dito ser perigoso pelos Yanomami; a 'imagem vital', bei a në ütübi, de uma pessoa morta igualmente o é para quem o matou (fazendo que o matador se veja obrigado a cumprir uma série de ritos de purificação e de proteção para evitar as agressões), pois, inconformado com o ato assassino e desejoso de vingar-se do matador, o bei a në ù tūbì do recém-falecido atormentará o matador sentando-se em seu peito e apertando-o com toda a força que conseguir.

Falta registrar que existe ainda, conforme explicam os Yanomami, uma interessante associação entre o bei a në utüubi de uma pessoa e seu sangue - tema que é, por seu lado, bastante desenvolvido na etnografia yanomami por Albert (1985). Cumpre acrescentar também que não pretendo discuti-lo aqui, mas tão-somente destacar alguns pontos que penso serem dignos de nota. $O$ primeiro fato digno de nota é que as agressões sofridas pelo bei a në ütübi de um homem ou de uma mulher devido a atos de feitiçaria estão relacionadas com a diminuição da quantidade de sangue em um organismo. Postula-se, assim, que as variações - positivas ou negativas - do volume de sangue no interior do corpo de um humano estão condicionadas às transformações fisiológicas que afetam o envelope corpóreo de uma pessoa (ALBERT, 1985 , p. 374). Já o segundo fato é que a mesma associação entre a imagem vital de uma pessoa e seu sangue remete, contudo, a uma teoria yanomami da predação imaterial que é inspirada, mais 
diretamente, em uma metáfora canibal, pois, segundo afirmam os Yanomami, a devoração da imagem vital é considerada como uma forma de hematofagia e, nesse sentido, penso que se poderia afirmar a predação simbólica de um dos constituintes de uma pessoa humana também é, por outro lado, uma predação biológica figurada. Se assim, tanto a devoração ontológica da imagem vital de um humano quanto a devoração biológica de seu sangue são concebidas, por esses índios, como partes de um mesmo processo simbólico, segundo uma teoria das ações patogênicas, tal como professada pelas pessoas desse povo (ALBERT, 1985, p. 346).

Por fim, falta comentar sobre a quarta dessas subcategorias que comporiam o conjunto espiritual bei ōshi: a bei a në rishibi. Diz-se entre os Yanomami que quem quer que nasça já nasce com uma espécie de 'alter ego' animal com o qual estará eternamente ligado, de tal modo que o destino de um é idêntico ao do outro: se um humano adoece, seu duplo animal também cai doente; se um homem ou uma mulher morrem, esta morte também significa, claro, a morte de seu bei a në rishibi. Descobre-se, então, que possuindo as mesmas qualidades, os homens herdam o seu duplo animal em linha paterna: este pode ser um jaguar, um macaco-bugio, uma harpia, etc.

Mas se a pessoa humana é uma mulher, o animal bei a në rishibi delas é sempre outro: um hããhããmi, um pequeno animal relativamente raro nas porções do território yanomami que se alimenta de caranguejos ${ }^{7}$. Mas isso não é tudo, pois os mesmos Yanomami que atribuem o bei a në rishibï de uma mulher ao hããhããmi também dizem, por outro lado, que o duplo animal de uma mulher também depende muito de suas características físicas: as mulheres altas e magras têm, por seu lado, a cobra como duplo animal. Já as que não são altas e magras, mas baixas e gordinhas, têm por duplo animal um sapo-boi, yoyo. Aquelas que não são nem baixinhas nem altas, nem gordas ou magras, mas que têm o rosto coberto de cicatrizes são ditas terem como duplo animal a anta.

Mas há ainda as mulheres que não têm, propriamente, um duplo

\footnotetext{
${ }^{7}$ Talvez se pudesse associar este fato com a ideia amplamente difundida entre os Yanomami de que a cata de caranguejos nos riachos pouco profundos é uma atividade exclusivamente feminina. Esta parece ser, em todo caso, a direção correta, pois como também intervém Lizot (2007, p. 291), a habilidade de uma mulher em caçar esses animais se julga, entre os Yanomami, como uma qualidade essencial às mulheres.
} 
animal, mas, ao contrário, uma espécie de duplo vegetal que é dito ser análogo às raízes de um cipó rai. Se já se disse que o duplo animal/vegetal e a pessoa que o corresponde têm o mesmo comportamento e o mesmo aspecto físico, se poderia afirmar que, para os Yanomami, as mulheres cujo duplo é a raiz do cipó rai se enredam os pés nos arbustos e na vegetação. Já as que têm o sapo-boi, yoyo, como duplo, têm predileção por ficar de cócoras sobre os troncos de árvores que encontram caídos pela floresta. Cumpre acrescentar que em todos os casos os duplos animais/vegetais dos humanos não vivem perto delas, mas distante, de forma que não há nenhuma interdição 8 alimentícia referente aos animais que representam os duplos humanos.

Passemos agora adiante à discussão do caso araweté, onde poderemos ver no processo da 'morte' da pessoa e na liberação da alma, $\tilde{i}$, uma situação similar à que se observou antes para os Yanomami. Dada a morte de uma pessoa humana, o corpo do recém-falecido - te'ó me'e (coisa morta); hete pe (ex-corpo); ou hiro pe (exrecipiente) - é a parte que apodrece. O corpo, ou melhor, a parte de uma pessoa humana que é transformada em um cadáver é dita ser itoyo me'e $r^{i}$, 'aquilo que apodrece', o que certamente não corresponde a dizer que esta parte não será devorada, uma vez que o próprio apodrecimento já é o sinal visível do canibalismo xamânico praticado pelos espíritos terrestres Ã̃̃ĩ e pela Iwi yari, Avó-Terra.

Da dupla divisão da alma, ĩ, de uma pessoa humana, libera-se o ta'o we (a partir do 'polo passivo' da alma, ta'o we rĩ, 'o que virará espectro'10), o duplo do cadáver que é dito surgir pelos Araweté no

\footnotetext{
${ }^{8}$ Há, sim, uma única exceção, que é o caso da harpia: quando um Yanomami mata uma dessas aves, o caçador tem que necessariamente submeter- se ao ritual de purificação dos homicidas, unokaimou. Bem, mas mesmo a interdição não implica que os humanos não possam comer da carne de animal. Certamente não é este o caso, mas quem o faz deve fazê-lo com toda velocidade e cuidar de deixar sempre um pouco de carne nos ossos do animal antes de jogá-los fora, tomando o cuidado de não deixá-los todos juntos, mas de espalhá-los totalmente. De certa forma, não parece haver diferença alguma entre aquele que por qualquer motivo consuma a carne da harpia, ou a carne de seu correspondente humano. Se não há diferença alguma, aqueles que comem da carne desse animal devem fazê-lo tal como os canibais o fazem quando executam uma vítima (LIZOT, 2007, p. 291).

${ }^{9}$ Nota-se entre os Araweté que tanto o cadáver de um humano quanto as cintas femininas e os chocalhos aray masculinos (distintivos sexuais e os únicos objetos enterrados junto com os mortos) são todos elementos englobados na categoria de itoyo me'e rĩ. São emblemas não transferíveis da singularidade individual que indicam a natureza do que certamente deve desaparecer: tudo que concerne à porção terrestre de uma pessoa. Ver Viveiros de Castro (1992, p. 200-201.

${ }^{10} \mathrm{O}$ ta'o we é, então, um corpo gerado a partir de uma sombra e é, logo, o inverso dos humanos vivos, cujo corpo físico é aquele que projeta uma sombra subordinada a ele. Já o ta'o we, como veremos, é somente uma sombra que se move livremente a partir de um corpo morto.
}

Espaço Ameríndio, Porto Alegre, v. 6, n. 2, p. 249-268, jul./dez. 2012. 
tempo e no espaço da morte; o espectro maligno que vagueia pelas margens da sepultura e segue, à noite, para a aldeia para atormentar os vivos, encostando-se neles com suas mãos geladas e paralisando-os, os crivando de um pavor agudo. Do ta'o we, cumpre acrescentar, ainda, que ainda que este seja um hete pe, ex-corpo, e uma bïde pe, expessoa, o espectro não é uma entidade imaterial. Pelo contrário, um ta'o we é um corpo no sentido físico do termo, um hiro' ${ }^{1}$, dotado de forma e de materialidade que se opõe à noção de alma, $\tilde{l}$, concebida como sombra ou imagem incorporal. Nesse sentido, se poderia sugerir sobre o ta'o we o seguinte: o ta'o we é a representação de uma pessoa morta, assim como ele também é, por outro lado, uma representação livre do defunto, dotada de um modo ser absolutamente sui generis, donde se poderia sugerir que o ta'o we é mais que uma imagem do morto, é um duplo deste. Isso de um lado. De outro, também poder-se-ia afirmar que o ta'o we é um puro-em-si, um corpo reduzido de seu estado de objeto, sem um sujeito, caracterizado antes por seu aspecto grotesco (é uma versão deformada dos humanos), mas, sobretudo, por seu comportamento repetitivo, mais do que por sua malignidade. Um ta'o we, como parecem estar certos os Araweté, não tem consciência. É apenas um morto-vivo que reage mecanicamente.

Pois bem. Isso acontece com o 'polo passivo' da alma. $O$ 'polo ativo' 12 do $\tilde{i}$ (que engloba as ideias de sombra, imagem, reprodução visual ou sonora e as pulsações vitais de um corpo), por outro lado, escapole por ocasião da morte de uma pessoa humana pela traqueia e pela moleira, e embarca na canoa de fibra de algodão dos deuses canibais Maï. Dada a chegada da alma no céu, segundo dizem os Araweté, os Maï se apressam para ver aquele que recém ascendeu aos céus. A nova alma é, então, pintada de jenipapo (seguindo um padrão similar ao usado pelos humanos vivos nas guerras) pelos 'filhos' e 'filhas' das divindades; e os Maï, mesmo curiosos, exigem presentes do

\footnotetext{
${ }^{11}$ Hiro, assim como $\tilde{\imath}$, tem significado posicional. Uma pessoa viva é hiro em oposição ao ta'o we. Um espectro é, por outro lado, um hiro, quando em oposição a uma imagem, $\tilde{l}$; e uma imagem é um hiro quando contrastado com as formas puramente subjetivas (VIVEIROS DE CASTRO, 1992, p. 203).

${ }^{12}$ Curiosamente a alma recebe vários epítetos no contexto escatológico araweté: ela é a iha me'e rĩ, 'a que irá' [para o céu]; é a Maï pihã nĩ, a 'futura companheira dos deuses'; como também é Maï đĩ ' 'futura divindade'; e a bïde rĩ ' 'futura pessoa' (contrastando com os ta'o we, que são reputados serem apenas bïde pe, ex-pessoas). Em todo caso, encontramo-nos aqui diante de uma noção que se refere tanto ao princípio vital quanto a uma espécie de 'imagem-sombra' dos humanos. Ver Viveiros de Castro (1992).
}

Espaço Ameríndio, Porto Alegre, v. 6, n. 2, p. 249-268, jul./dez. 2012. 
$\tilde{I}$, como penas de cotinga, tucano e arara. Se a alma é de uma mulher, o 'presente' exigido é, em todo caso, outro: os Maï proporão que ela transe com eles. Já que os humanos sempre recusam e nunca cedem aos Maï os presentes que tanto desejam - seja por medo, avareza, estupidez, ou simplesmente por raiva de terem falecido -, os deuses prontamente os matam: crivam um homem de flechas, ou quebram os pescoços das mulheres. O comportamento agressivo ${ }^{13}$ dos Maï para com os humanos refere-se ao fato de os recém-falecidos serem reputados pelos Maï se conduzirem sem civilidade alguma nessa 'terra estrangeira' que acabaram de chegar, uma vez que se recusam a entrar em relação com os donos do céu por meio do único modo de que dispõem: dando-Ihes tudo o que têm como sinal de boa vontade. Nesse sentido, a alma de um defunto no céu é dita ser, sobretudo, um estranho, um inimigo, Awĩ.

Para solucionar este desejo ambivalente, só há, portanto, uma solução: a morte e o canibalismo ${ }^{14}$. Uma vez executada, a vítima é esquartejada e cozida em uma enorme panela de pedra pela Maï Đari, Avó-Divindade (o equivalente celeste da Avó-Terra, terrestre e canibal), e todos os Maï hete comem de sua carne. Já a pele que a recobria, quando já removida, é posta para secar ao sol e é mantida como uma espécie de troféu para os deuses. Os ossos são cuidadosamente separados e rearranjados, pois é justamente a partir deles que a divindade Tiwawï recomporá um novo corpo para a alma, agora completamente livre de carne humana. Feito isso, o novo corpo é prontamente carregado para o ođipiđa kã, para um banho em água efervescente (não há fogo) que muda a pele da alma e a revive,

\footnotetext{
${ }^{13}$ Ressalte-se que não é apenas por sua avareza e mesquinhez que os mortos são tratados como inimigos pelos Maï. Uma interpretação adicional de Viveiros de Castro (1992, p. 211) vem-nos lembrar que os deuses manifestam uma dupla agressividade: eles estão com raiva da própria alma por estar morta - os mortos, quando mencionados pelos Araweté, são descritos como seres feios, mal-cheirosos e recalcitrantes em aceitar a sua condição -; mas também estão com raiva por causa dos mortos, já que os Maï os cobiçam avidamente, eles ha'o we pitã hetĩ, 'desejam muito os mortos'.

${ }^{14}$ Há ainda outra possibilidade somada no pensamento araweté. Quando o caso é outro e um guerreiro é quem morre, ele não libera nenhum $t a$ 'o we e tampouco é devorado pelos deuses celestes. Um guerreiro já é, por si próprio, divino. Ele é, por seu lado, uma espécie de divindade antecipada (como o xamã é, por seu lado, um 'morto antecipado', capaz de controlar ativamente a leveza da alma) que garante ainda em vida uma transformação que, para o resto dos humanos vivos, só se dá após a morte. Se, como demonstrou Sztutman (2005, p. 73) sobre os antigos Tupi, a pessoa ideal é aquela que tem a capacidade de controlar o que nela é outro e, assim, tem o poder de reunir em seu corpo várias subjetividades diferentes, a figura do guerreiro araweté culmina em uma plenitude: ele é humano e divino ao mesmo tempo.
}

Espaço Ameríndio, Porto Alegre, v. 6, n. 2, p. 249-268, jul./dez. 2012. 
transformando-a inteiramente e fazendo dela uma criatura forte, jovem e bonita, como os próprios Maï. Pintam, então, as almas dos homens, novamente com tintura de jenipapo realizada em motivos gráficos que obedecem a padrões absolutamente finos e delicados. Quando a alma é a de um morto do sexo feminino, é a nova vagina da moça que é tingida pela cor azulada característica da tintura de jenipapo oxidada. Desde o odipida $k A$, as almas transformam-se em seres imortais, ou melhor, em seres eternamente jovens, pois assim que começam a envelhecer, são submersas no ođipiđa kã, para que possam mudar de pele, para que novos dentes possam crescer em suas gengivas e para que o pênis recupere o vigor e a elasticidade.

Sucede, depois da devoração pelos Maï hete e do banho de rejuvenescimento a que é submetido o novo corpo do morto, o seguinte: a raiva dos mortos se encerra, eles acabam por se casar com uma esposa/marido celeste e passam a estabelecer relações de amizade com os deuses. Com o corpo impregnado de novos perfumes, os mortos gradualmente deixam de se lembrar das pessoas humanas da terra e, nessas condições, não seria de todo errado dizer que o banho de rejuvenescimento também é um tipo de banho de esquecimento ${ }^{15}$. Por último, é importante salientar, ainda, que, tal como se disse para os ta'o we, o $i$ também não é uma abstração. Ele é, em certa medida, uma imagem corporada (i.e. feita um corpo), um hiro, quando se encontra fora e distante dos corpos dos humanos vivos, como ocorre, por exemplo, nos sonhos, na morte e nas situações de roubo de alma

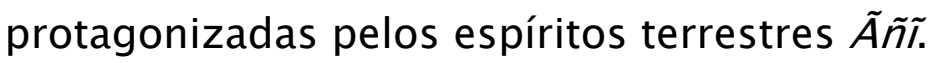

\section{A propósito do Anti-Psiquê}

Esses fatos extraídos das etnografias yanomami e araweté sobre a noção de alma tomada enquanto um tipo de imagem que se presentifica

\footnotetext{
${ }^{15}$ É, no entanto, digno de nota que somente quando os vivos finalmente se esqueceram dos mortos que alguém poderia afirmar que o morto se esqueceu realmente dos vivos. Ora, mas se o banho de rejuvenescimento também é um banho de esquecimento, creio que também não seja errado sugerir que esquecer-se é, antes de tudo, transformar-se em; em outras palavras, esquecer-se dos vivos corresponde a transformar-se em um Maï genérico e em um ancestral genérico, pirowi hã. E isso não é só: os mortos, quando devorados e rejuvenescidos pelo banho de imersão no ođïpiđa $k A$, já estão prontos para se casarem com os Maï.
}

Espaço Ameríndio, Porto Alegre, v. 6, n. 2, p. 249-268, jul./dez. 2012. 
em determinadas situações e que não é nem uma metáfora e nem uma dimensão imaginária do corpo de uma pessoa humana, mas é, antes, uma dimensão que só se atualiza de fato como um corpo perante uma 'mudança de circuito', isto é, quando a alma perde o lastro que a liga ao corpo físico e se relaciona com formas não humanas de alteridade, evocam diretamente, como mencionei anteriormente, algumas ideias como as 'imagem cristal'; 'região de indiscernibilidade'; ou as faces 'atual' e 'virtual', com as quais Deleuze (1990, p. 103) argumentou em favor de uma imagem que se constituísse em torno de um ponto de indiscernibilidade entre duas imagens distintas, a atual e a virtual, e que fosse capaz de fazer visível o próprio tempo, ou, como se exprimiu este autor, "um pouco de tempo em estado puro" (DELEUZE, 1990, p. 103), por intermédio da distinção entre essas duas imagens que nunca acaba de se reconstituir.

Este cristal, de acordo com Deleuze (1990, p. 102), não cessa de trocar as duas imagens distintas, mas indiscerníveis, (a atual do presente que passa e a virtual do passado que se conserva) que o constituem. Isso é um ponto. O que também é digno de nota é a objetividade atribuída ao atual, mas se o atual é sempre objetivo, o virtual é o subjetivo: primeiramente afeto e depois o próprio tempo, pura virtualidade desdobrável em afetante e afetado (DELEUZE, 1990, p. 104). No fim, concluir-se-ia que a imagem-cristal está sempre em formação e crescimento e, logo, nunca está acabada. Todo cristal se faz continuamente e só o faz porque haveria de existir um 'germe' que incorpora o meio e o força a se cristalizar (DELEUZE, 1990, p. 110). Assim sendo, se poderia dizer que o cristal por inteiro é apenas "o conjunto ordenado de seus germes ou a transversal de todas as suas entradas" (DELEUZE, 1990, p. 111), cuja ordenação é bifacial e envolve o germe. No fim, se algo poderia ser dito a respeito da imagem-cristal (uma imagem que é cristal...), é que vemos nela sempre "o jorro da vida, do tempo, em seu desdobramento ou diferenciação" (DELEUZE, 1990, p. 113).

Como apenas anunciei acima, é nesse contexto teórico que eu situaria a ideia de Anti-Psiquê. Entretanto uma noção como essa nos coloca questões que a análise baseada em tropos nos impediria de localizar (tal como argumentou Lima (1996) a propósito da noção de 
ponto de vista). Nesse mesmo sentido, noções como as de metáfora e metonímia não têm tanta serventia (ou mesmo nos atrapalham) para nosso objetivo de determinar a lógica subjacente da noção indígena de alma e sua relação com o corpo de uma pessoa humana.

Entre todas as proposições a respeito da noção de alma tal como mobilizada pelos ameríndios, as etnografias yanomami e araweté nos apresentam, particularmente, essas duas: a alma Araweté, ĩ é vista como um corpo, hiro, pelos deuses Maï, que a consideram como um inimigo com quem lidam via canibalismo; a bei a në borebł de um Yanomami doente/adormecido pode ser agredida por seres não humanos, figurando como causa para o sofrimento e as patalogias que poderão acometer uma pessoa. Assim, do ponto de vista de outrem, uma alma é um corpo cujas afecções ou acarretam sofrimento para o corpo físico ao qual estão atreladas, ou, quando o caso é outro e não há mais ligação entre o corpo físico e a alma, cessa sua humanidade e ela se transforma em outra coisa que não um humano.

Contudo, ao invés de tomar estas equações como expressões que justificassem a interpretação da noção de alma enquanto uma figura que representa o todo do corpo físico de uma pessoa humana, me parece existir outro caminho, pois se o problema se resumisse a um caso de sinédoque, talvez os Yanomami e os Araweté não estabelecessem outras possibilidades reais/materiais de existência que não a da alma tomada enquanto princípio de abstração e de representação do corpo de uma pessoa (uma sombra, o princípio vital que anima os corpos das pessoas, uma gravação, o sangue, etc.). Assim sendo, mais que cartografar as relações simbólicas entre corpo, alma e formas não humanas de alteridade, o que proponho aqui é a busca de uma noção por meio da qual se possa explorar (novamente a exemplo do que comentou Lima (1996) a respeito da noção de ponto de vista, na qual reconheço a 'paternidade' da ideia de um Anti-Psiquê) as condições culturais de verossimilhança de equações como essas, que são operativas no universo desses povos ameríndios.

O Anti-Psiquê envolve, pois, uma certa concepção segundo a qual uma alma só se atualiza como corpo perante os olhos de outrem diante de uma 'mudança de circuito'. Mais precisamente, trata-se da mudança 
de um circuito 16 humano, caracterizado como o domínio da consanguinidade no qual o corpo e a alma articulam-se ao redor de uma 'região de indiscernibilidade', determinado pelo maior grau de contração 17 entre estes, a um circuito não humano, caracterizado como os domínios da inimizade e da afinidade potencial - marcado pelas relações entre uma pessoa humana e espíritos não humanos que capturam os humanos, desejosos de transformá-los em um parente -, nos quais a relação entre corpo e alma é determinada por um grau menor de contração, mas sem que este circuito maior deixe de se remeter sempre ao pequeno circuito humano. A conclusão é clara: quanto maior a amplitude do circuito, mais efetiva a "predação ontológica" (ou transespecífica) (FAUSTO, 2002, p. 16) que produzirá enfermidades e/ou desencadeará uma transformação concebida como uma passagem da humanidade à não humanidade.

Diríamos, pois, que a existência de tal 'região de indiscernibilidade' determinaria o menor circuito em que o corpo de uma pessoa humana e sua alma podem se entreter. Entretanto esta é uma formulação perigosa, pois poderia conduzir facilmente ao equívoco de acreditar que ambos são confundíveis e que constituem, no fim, uma única e mesma coisa. Pelo contrário, o que as etnografias yanomami e araweté nos sugerem é que há uma diferença fundamental entre o corpo físico e a alma de uma pessoa humana que faz com que, mesmo que sejam indiscerníveis, contemporâneos e coexistentes, eles não se confundam um com o outro. Em outras palavras, a diferença entre eles é permanente, fazendo da passagem da dimensão do corpo físico à dimensão da alma algo necessário e inescapável (e por que não dizer algo constituinte das próprias sociocosmologias indígenas, vide o caso araweté), mas fazendo também com que cada uma dessas duas faces de uma pessoa humana persiga incessantemente a outra.

\footnotetext{
${ }^{16} \mathrm{O}$ que está sendo chamado de 'circuito' aqui refere-se a uma espécie de linha temporal sociocósmica em que estão inseridos os humanos e os não humanos, no interior da qual se disputam, como sugeriu Fausto (2002, p. 14), potencialidades de existência.

${ }^{17}$ Apresso-me em sublinhar que a determinação desses circuitos e de sua amplitude só é pertinente aqui se considerada do ponto de vista dos humanos. Considerando-se que alguns animais e alguns espíritos também são capazes de ocupar pontos de vista (VIVEIROS DE CASTRO, 1996; LIMA, 1996), caso a determinação desses circuitos se desse a partir do ponto de vista dos animais ou dos espíritos, por exemplo, tal determinação certamente ganharia outros contornos.
}

Espaço Ameríndio, Porto Alegre, v. 6, n. 2, p. 249-268, jul./dez. 2012. 
Mas há ainda algo que precisa ser ressaltado à ideia de AntiPsiquê nesse contexto de 'atualização' da dimensão da alma de uma pessoa humana apresentado nas etnografias yanomami e araweté. A alma - tal como argumentou Lima (1996, p. 37) a respeito da ideia de alma tal como mobilizada por outro povo tupi, os Yudjá - é invisível, sem que isso acarrete sua imaterialidade. Alma e corpo são, na realidade, como sugere a autora, menos substâncias que efeitos de perspectivas que operam por intermédio da noção de ponto de vista articulando duas dimensões da experiência humana (que poderiam ser chamadas, então, do ponto de vista dos humanos, de Natureza e Sobrenatureza). Quando se trata da experiência da alma nas etnografias yanomami e araweté, esta não consiste absolutamente (como já havia intervindo Lima (1996, p. 35) acerca da etnografia yudjá) em consciência de si enquanto sujeito, pois uma alma tomada enquanto sombra/princípio vital/pulsação sanguínea é uma parte do eu que é, por seu lado, incapaz de explicar as razões por que o eu é uma pessoa (LIMA, 1996).

Deduz-se, portanto, que a experiência da alma enquanto uma dimensão corporal atualizada em outro 'circuito' não é de subjetividade. Mas isso, de novo, de um lado. De outro, a alma é um princípio 'corporado' e um duplo humano e/ou animal (quando o caso é o da etnografia yanomami) que escapa do sujeito e se furta, nesse mesmo movimento, da pura representação do corpo físico de uma pessoa. Novamente aqui, a experiência da alma humana também não é de subjetividade ${ }^{18}$, visto que ter consciência integral dos eventos ocorridos com a alma de uma pessoa implica, no limite, que o corpo físico dessa mesma pessoa já não está mais ativo. Em outras palavras, isso se poderia afirmar assim: o conhecimento integral da vida da alma de uma pessoa só é atingível depois que essa pessoa morre. Até lá, uma pessoa humana só pode experienciar parcialmente esse conhecimento, uma vez que a dimensão da alma se atualiza em outros circuitos e seus atos ressoam no corpo físico da pessoa sem que ele ou ela tenha real vivência desse acontecimento.

\footnotetext{
${ }^{18}$ Ainda que Lima (1996) tenha notado em sua etnografia realizada entre os Yudjá que alguns fragmentos da alma de uma pessoa humana possam vir a preencher a consciência.
}

Espaço Ameríndio, Porto Alegre, v. 6, n. 2, p. 249-268, jul./dez. 2012. 
Pois bem. Tomada de outro ângulo, há de se ressaltar que a experiência (integral ou não) do conhecimento da vida da alma depende da ruptura (seja ela momentânea ou definitiva) do esquema sensóriomotor ao qual um corpo e uma alma estão ligados. Agora, a ruptura desse esquema inscreve a alma tal como mobilizada pelos Araweté e pelos Yanomami em outra modalidade de tempo: um tempo não cronológico que arrasta consigo uma série de imagens do cosmos inacessíveis a uma pessoa em condições normais, nas quais o motivo principal que as constitui é quase sempre a relação com formas não humanas de alteridade. A estrutura que a noção de Anti-Psiquê permite configurar é feita, então, sobretudo, de tempo. A exemplo da noção indígena de ponto de vista (LIMA, 1996 e 2005), os aspectos que constituiriam a noção de Anti-Psiquê também são pelo menos duas linhas espaço-temporais. Nesse sentido, se a vida da alma (diferentemente da vida do corpo) não é uma experiência de subjetividade, isso é porque ela se dá em uma linha paralela de tempo, onde a alma se engaja em um acontecimento novo. Desse modo, a alma à qual um acontecimento é referenciado não é (tal como um sujeito) um centro em torno do qual todo o mundo se encurva. Se a alma é sujeito, ela só o é no sentido lato: um 'quase-sujeito' disperso no tempo e espaço do cosmos, que aparece duplicado entre a vida da própria alma e a vida do corpo físico, repartido, então, entre Natureza e Sobrenatureza, complexificado pela presença de Outrem.

\section{Conclusões}

A fim de alinhavar algumas conclusões sobre a ideia de AntiPsiquê, eu gostaria, ainda, de ressaltar alguns pontos:

(1) Através do estudo da noção de alma nas sociocosmologias yanomami e araweté, tentei mostrar que podemos compreender a ideia sobre o Anti-Psiquê como a manifestação de uma propriedade positiva das cosmologias indígenas, a saber, uma dimensão corporal de uma pessoa humana atualizada perante uma mudança de circuito que persegue continuamente a face física do corpo de uma pessoa humana, mas que não se remete a ele nem como subjetividade nem como 
representação, pois o que dá consistência a essa ideia não é a experiência subjetiva, mas, antes, o delineamento de pelo menos duas formas distintas de espaço/tempo.

(2) Todo acontecimento referenciado a uma alma supõe uma contraefetuação: uma passagem da dimensão física à dimensão anímica que não exclui, por outro lado, o movimento reverso - a passagem da dimensão anímica à dimensão física - por meio da afirmação do próprio acontecimento. A contraefetuação é, nesse caso, um acontecimento paralelo a outro transcorrido em outro momento e em outro lugar.

(3) Tentei caracterizar sob a marca da ideia de Anti-Psiquê as relações nas quais a alma não mais engaja-se em uma relação figurativa com o corpo ao qual está atrelada, mas, antes, em relações 'problemáticas' (ou 'teoremáticas'), nas quais o pensamento torna-se imanente à alma por meio da atualização desta em outra linha espaçotemporal que não a dos humanos vivos. Decorre desse 'movimento aberrante' de atualização a suspensão do próprio mundo indígena por meio da proliferação de imagens do cosmos que se dirigem àquilo que não se deixa pensar normalmente no pensamento nem se ver, em condições normais, na visão. As linhas espaço-temporais remetem, nesse sentido, ao ato de ver na visão própria de uma vida específica (a do corpo ou a da alma) e ao ato de pensar próprio do pensamento de cada uma dessas vidas.

\section{Referências bibliográficas}

ALBERT, Bruce. Temps du Sang, Temps des Cendres: Représentation de la maladie, système rituel et espace politique chez les Yanomami du sud-est (Amazonie brésilienne). 1985. 729 f. Tese (Doutorado em Antropologia) - Université de Paris X, [1985].

ALBERT, Bruce; KOPENAWA, Davi. La chute du ciel: paroles d'un chaman yanomami. Paris: Plon, 2010.

DELEUZE, Gilles. A Imagem-Tempo. São Paulo: Brasiliense, 1990. 
FAUSTO, Carlos. Banquete de gente: comensalidade e canibalismo na Amazônia. Mana, Rio de Janeiro, v. 8, n. 2, p. 7-44, 2002.

GRÜNEWALD, Leif. Cartografia das Almas: imagem ameríndia e estética da nãorepresentação. 2011. 143 f. Dissertação (Mestrado em Antropologia Social) Universidade Federal Fluminense, [2011].

LIMA, Tania Stolze. O dois e seu múltiplo: reflexões sobre o perspectivismo em uma cosmologia Tupi. Mana, Rio de Janeiro, v. 2, n. 2, p. 21-47, 1996.

Um peixe olhou para mim. São Paulo: Editora UNESP, 2005.

LIZOT, Jacques. El Mundo intelectual de los Yanomami: cosmovisión, enfermidad y muerte con una teoría sobre el canibalismo. In: FREIRE, Germán; TILLET, Aimé (Orgs.). Salud Indígena en Venezuela. Caracas: Dirección de Salud Indígena, 2007. p. 269-322. v. 1

SZTUTMAN, Renato. O profeta e o principal: a ação política ameríndia e seus personagens. 2005. 456f. Tese (Doutorado em Antropologia Social) - PPGAS, USP, [2005].

VIVEIROS DE CASTRO, Eduardo. From the enemy's point of view. Chicago: University of Chicago Press, 1992.

Pronomes cosmológicos e o perspectivismo ameríndio. Mana, Rio de Janeiro, v. 2, n. 2, p. 115-144, 1996. 